\title{
Impact of an Augmented Reality System on Students' Learning Performance for a Health Education Course
}

\author{
Ya-Ming Shiue ${ }^{1}$ \\ *Yu-Chiung Hsu ${ }^{2}$ \\ Meng-Huei Sheng ${ }^{1}$ \\ Cheng-Hsuan Lan ${ }^{1}$

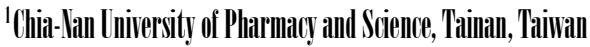

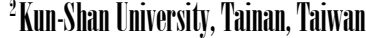

\begin{abstract}
In recent years, the innovative applications of integrated augmented reality (AR) into educational settings had increased rapidly in Taiwan. AR provides the scene of the real world while interacting with the virtual and physical objects and increases study that investigated the middle-school students learning health education courses related to human body structure knowledge integrating AR technology with different learning style preferences. A two-way t-test was applied to examine the experimental (AR-based) or control (traditional lecture) group in health education courses for four consecutive weeks, comparing with pre-test and post-test scores. The findings revealed that students in the AR experimental group apparently had a higher learning achievement than the students in the control group. Moreover, students with different learning styles had the significant differences in learning achievement. The research outcomes provided the practical implications for educators in incorporating AR applications for enhancing learning motivation and to study the differences in students' learning style.

Keywords: Augmented reality, learning style, learning achievement, health education, human body structure

JEL:D83, I10, I23
\end{abstract} \\ students' learning motivation. This paper presents an empirical
}

Researchers and teachers agree that educational technology is changing the way students engage and interact with learning material (Demir, 2015). Roussou (2004) mentioned that the effectiveness of students' learning is interactivity. The interactivity is defined as the extent to which users can participate in modifying the form and content of a mediated environment. In addition, the development of students' perception of science has been considered to be the primary importance of learning and continues to influence their further education (Lee, 2010). Therefore, it is important to create meaningful learning environments where the students can use their abilities to learn, grasp complex concepts, and acquire knowledge through observation, imitation and participation.

In traditional health education on understanding human body structure, learning can be achieved by attending lecture courses. Many of the standard human body textbooks only publish two-dimension pictures with narrative expression which might not convey required graphical information to middle- 
International Journal of Management, Economics and Social Sciences

school children. It is abstract and difficult to facilitate students to learn more complex parts of the body structure and recall the subject in such passive learning approaches. Ganguly (2010) suggested that human body didactic lectures were less attractive to students and could not generate long lasting understanding. Hence, the goal to understanding body structure is not limited to increase students' health education knowledge, but also to promote healthy behavior that can create positive attitudes toward the own health knowledge. In addition, students will keep long-lasting understanding if they are able to conduct experiments and transfer concepts into long-term memory.

Augmented reality (AR) refers to technologies that enhance the sense of reality, allowing the coexistence of digital information and real environments (Yen, Tsai and $\mathrm{Wu}, 2013$ ). AR has been recognized as a technology with great potential for facilitating learning. Students are able to freely navigate in a virtual environment, observe the phenomenon from different perspectives, and interact with selected virtual objects. Visualization and interaction provided by AR have been successfully used to improve spatial abilities and to help learners to understand abstract concepts (Ibáñez et al., 2014). Researchers proposed that the AR supports students in learning complex subjects, such as the human body and anatomy (Jamali et al., 2015). It allows the coexistence of digital information within a real environment that reduces cognitive load and facilitates students' learning process.

Bacca et al. (2014) suggested that AR are more interesting than existing learning methods, making students more active to learn and thus can improve learning. This study uses AR to create an interactive learning environment, which allows students to understand the 3D human body structure with visual support. Students can easily get the relative position of each internal human organ in different angle in an interactive 3D model. However, the potential of $A R$ in health education remains unexplored, and there is a limited amount of research investigating students' learning style preference with the use of AR.

Comparing with the traditional health education courses, AR technology provides opportunities for students to investigate the 3D human body structure with vivid learning experience rather than teachers' lecture and textbooks. However, little research on AR had been conducted in the field of health education and analyzed the learning outcomes. Our purpose to conduct this study is to apply AR technology in middle-school health education courses dynamically presenting with different angles to visualize and create a student-centered learning environment. Therefore, we would like to investigate the impact of AR technology on middle-school students' learning human body knowledge outcomes.

\section{LITERATURE REVIEW}

\section{Augmented Reality and Its Applications in Learning}

The term augmented reality (AR) is a technology that allows computer-generated virtual imagery info- 
rmation, combining the real world with virtual worlds, providing interaction, and presenting threedimensional objects (Azuma, 1997). Virtual objects used in AR may include text, images, video clips, sounds, 3D models, and animations. Ideally, these virtual objects will be perceived as coexisting within a real-world environment. AR applications can be viewed using various devices, such as a see-

through head-mounted display (HMD), a desktop, laptop computer, or a mobile device with one camera.

According to Azuma et al. (2001), AR technology is characterized by three properties:

1. Combine real and virtual objects in a real environment.

2. Align real and virtual objects with each other.

3. Run interactively and in real time.

The attention that $A R$ is receiving through the increase in educational applications by providing interesting features, such as immersion, interaction and navigation are expected to improve both students' satisfaction and knowledge comprehension. AR has been used to develop students' understanding of science, including microbiology (Chen, 2006), biomedical science (Rasimah, Ahmad and Zaman, 2011), and natural science (Tarng and Ou, 2012). The use of AR technology enable students to interact with real objects they want to explore and offer better opportunities of learning-bydoing through physical movements in rich sensory spatial contexts (Dunleavy, Dede and Mitchell, 2009). Research revealed that the immersive and interactive capabilities foster student motivation and engagement (Huang, Rauch and Liaw, 2010) and are potentially useful in learning tasks that require experimentation. A key pedagogical affordance of $A R$ is the ability to rescale virtual objects, allowing students to better understand through manipulation the properties and relationships of objects that would be difficult to examine effectively, otherwise. Therefore, students can have opportunities to perform experiments in more interactive and realistic ways and apply the knowledge and skills they learned.

\section{Learning Style}

Learning style refers to the individuals' learning preference for receiving information in any learning environment. Campbell, Campbell and Dickinson (2003) defined learning style as a certainly specified pattern of behavior according to which the individual advances his learning experience. Brown, McNeil and Glenberg (2009) also believes that learning is a kind of consistent patterns and lasting (enduring) tendencies. To some extent, learning style can be contributed to learners' variation and different needs (Wang, 2007). Understanding the preferred learning style is crucial to designing the technologyassisted learning environment effectively.

In the field of education, the recognition of learning style is important for both teachers and 
International Journal of Management, Economics and Social Sciences

students. Fenrich (2006) states that instructional designers must consider learners' learning styles when they are designing certain syllabus and material in order to achieve the maximum learning state of students. Accordingly, students can also benefit from understanding their learning style preferences, which can help them to strengthen their knowledge acquisition and influence their academic achievements positively (Popescu, 2010; Shaw, 2012).

There are different learning style theories proposed by researchers, such as those proposed by Keefe (1987), Kolb (1984), and Felder and Silverman (1988). In this study, Felder and Soloman (1991) Index of Learning Style (ILS) is used, which is based on Felder and Silverman (1988) Learning Style Model (LSM). The reason for choosing ILS for this study was that it has been developed specifically for students and has established reliability and validity particularly for educational settings (Felder and Spurlin, 2005). The ILS classified students into four dimensions of learning styles that identifies a student's learning preference i.e., active/reflective, sensing/intuitive, visual/verbal, and sequential/global. Active and reflective styles refer to processing dimension, sensing and intuitive styles refer to perception dimension, visual and verbal refer to input dimension, and sequential and global styles refer to understanding dimension. With the emergence of AR technology, the influence of learning styles on technology-enhanced active learning environment is still at a beginning stage.

Each student's learning pattern may have more or less difference, so finding out the unique learning patterns of students to enhance learning efficiency is also one of the priorities of teachers to teach the students effectively. Dunn, Beaudry and Klavas, (2002) stated that students' achievement increases when teaching methods match their learning styles for learners at all levels from primary school to adulthood. AR has been recognized as a technology with great potential for learning science (Bujak et al., 2013; Cheng and Tasi, 2012; Wu et al., 2013) as it provides new ways of tactile and visual interactions which could be useful to improve learning outcome.

Although AR is gradually being adopted to support traditional learning materials in school, visualization features of $A R$ have been successfully used to improve spatial abilities in science (Cuendet et al., 2013; Martin-Gutierrez et al., 2010). It does not seem reasonable to conclude that the sole use of technology would bring positive attitudes and better performance for all the learners despite of different characteristics. Therefore, there is a lack of studies with a focus on investigating learning styles and learning achievement in the educational AR environment.

\section{Purpose of the Study and Research Questions}

This study aimed to investigate health education courses of the human body structure in an AR learning environment versus traditional learning environment related to learners' individual learning styles and learning performance. To fulfill the objective of this study, the following questions were 


\section{Shiue et al.}

raised to be answered:

1. Is there any difference in students' learning performance in health education courses between augmented reality-based and the traditional learning environment?

2. Which learning style would influence students' learning performance in the augmented reality learning environment and in the traditional learning environment?

Moreove, the following null hypotheses were formulated for answering the research questions:

$\mathrm{H}_{1}$ : There is no significant relationship between learners' learning performance in the augmented reality and traditional learning environment related to health education courses.

$\mathrm{H}_{2}$ : No specific learning style contributes to better performance in the AR learning environment and the traditional learning environment.

\section{METHODOLOGY}

\section{-Design of Experiment}

This study used AR to create an interactive learning environment, which allows students to understand the 3D human body structure with visual support. Students can easily get the relative position of each internal human organs in a different angle in an interactive 3D model. This study compared two learning environments for 3D human body structure with visual support of AR learning environment. A pretest/post-test design was used to explore the effect of students' achievement as measured by knowledge test on basic concepts. Furthermore, we investigated the influences of learning styles for applying AR in a learning environment which has not yet been explored.

\section{-Participants}

The subjects included two classes of eight grade middle-school students in Tainan City in Taiwan. A total of 88 students voluntarily participated in the study, 40 were boys and 48 were girls. One class was randomly assigned to be the experimental group with AR learning environments and the other was assigned to the control group with traditional learning environments. The experimental group, including 45 students of which 21 were boys and 24 were girls. The control group consisted of 43 students, of which 19 were boys and 24 were girls. The students were taught by the same instructor who had taught health education courses for more than ten years.

\section{-Instruments}

The Index of Learning Style (ILS) was developed by Felder and Soloman (1991), which is based on Felder and Silverman (1988) Learning Style Model. The ILS is a 44-item instrument in which each of the four learning styles dimension contains 11 items. The ILS may be categorized into four dimensions 
of learning styles that identifies a student's learning preference in perceiving, processing and understanding information as well as his or her preference of information input source. These associated categories are as follows: processing (active/reflective), perception (sensing/intuitive), input (visual/verbal), and understanding (sequential/global).

The learning achievement tests were developed by the experienced instructor who taught natural science course for more than ten years. The pre-test was employed to evaluate students' prior knowledge related to human body structure knowledge. It contained yes/no questions, multiple choice and fill-in-blank items, giving a score of 100 . The post-test contained the similar format, and total scores were also 100. The reliability values of the pre-test and post-test were 0.72 and 0.81 , respectively.

\section{-Procedure}

The study was conducted over four weeks of middle-school health education courses of the human body structure in Taiwan. The course taught the basic principle of light by the same instructor. At the beginning of the course, the students took the, ILS learning style inventory and the pre-test. One class was randomly assigned to the experimental (AR-based) group and another class was assigned control (tradition) group. In each group, students completed the five stages of the learning activities followed the same curriculum. During the four weeks of health education courses, the students in the experimental group learned with the AR learning material; on the other hand, those in the control group learned with the traditional learning environments, such as lecture and slides presentation. After the end of the health education course, the students took the post-test.

\section{ANALYSIS AND RESULTS}

Applying ANCOVA to assess differences in learning outcomes with augmented reality technology, the mean pre-test of the experimental group is 68 , and of the control group is 70 . Therefore, it can be concluded that there is no difference $(f=0.32, p>.05)$ in the pretest between the experimental group and the control group, but significant differences $(f=30.2, p<.05)$ in the post-test. Having applied augmented reality technology in class teaching, the mean post-test of the experimental group was 85 , obviously increased by 17 . However, the mean post-test of control group was 77 which was higher than pre-test by 7 , did not reveal significant differences on the post-test. Students in the AR learning environment showed significant increase in learning achievements than those who in the traditional learning environment. Results are provided in Table 1.

The assessment of students' learning style preferences in both AR based and traditional learning environments, as shown in Table 2, indicated that on two dimensions: active-reflective $(A-R)$ and 
sensing-intuitive $(\mathrm{S}-\mathrm{N})$ there was no significant difference in distributions of students. However, in the case of visual-verbal and sequential-global $(S-G)$ dimension, there was significant difference $\left(\chi^{2}(1)=\right.$ $\left.8.1, p=.01 ; \chi^{2}(1)=9.5, p=.008\right)$ in distributions of students.

\begin{tabular}{cccccccc}
\hline & Group & $\boldsymbol{n}$ & Mean & SD & $\begin{array}{c}\text { Adjusted } \\
\text { Mean }\end{array}$ & SE & $\boldsymbol{f}$ \\
\hline Pre-test & Experimental & 45 & 68 & 10 & 11.3 & 1.1 & .32 \\
& Control & 43 & 70 & 11 & 12.3 & 1.3 & \\
Post-test & Experimental & 45 & 85 & 9 & 8.2 & 1.1 & $30.2^{*}$ \\
& Control & 43 & 77 & 12 & 9.1 & 0.8 & \\
\hline
\end{tabular}

Source: Calculated for this study

${ }^{*} p<0.05$

Table 1. Pre-test and Post-test ANCOVA Results

\begin{tabular}{cccccc}
\hline & Dimension & $\boldsymbol{n}$ & $\mathbf{\%}$ & $\boldsymbol{\chi}^{\mathbf{2}} \mathbf{( 1 )}$ & $\boldsymbol{p}$ \\
\hline $\mathrm{A}-\mathrm{R}$ & Active & 45 & 51 & 1.2 & .30 \\
& Reflective & 43 & 49 & & \\
$\mathrm{~S}-\mathrm{N}$ & Sensing & 51 & 58 & 2.5 & .50 \\
& Intuitive & 37 & 42 & & \\
$\mathrm{Vs}-\mathrm{Vb}$ & Visual & 58 & 66 & 8.1 & .01 \\
& Verbal & 30 & 34 & & \\
$\mathrm{~S}-\mathrm{G}$ & Sequential & & & & \\
& Global & 27 & 30 & & \\
& & 61 & 70 & & \\
\hline
\end{tabular}

Source: Calculated for this study

Table 2. Students' Learning Style in both Learning Environments

The mean score of post-test achievement among participants with different learning style dimensions (active-reflective, sensing-intuitive, visual-verbal, sequential-global) was compared using independent sample t-test in the augmented reality learning environment. Table 3 shows that that significant effects were obtained in two dimensions of learning styles (active/reflective and visual/verbal) when post-test mean score was the dependent variable in the AR learning environment. The active learners had a better performance than reflective learners. In addition, the visual learners outperformed than verbal learners in the AR learning environment. Although, the sensing learners had the higher mean score than intuitive learners and the sequential learners had the higher mean score than global learners, there was no significant difference in the AR learning environment.

\section{CONCLUSION}


This study aimed to investigate the academic achievement of different learning styles compared with AR and traditional learning environments. After conducting a statistical analysis on the pre- and posttest scores, it was found that students who applied AR application performed significantly better than those who were taught in the traditional environment. The findings seem to support the outcomes of previous research studies (e.g., Lin et al., 2013), which showed that AR technology contributed to improving achievement compared to traditional learning environments.

\begin{tabular}{ccccc}
\hline Dimension & $\boldsymbol{n}$ & Mean & SD & $\boldsymbol{p}$ \\
\hline Active & 23 & 88.87 & 2.5 & .03 \\
Reflective & 22 & 86.12 & 4.9 & \\
Sensing & 19 & 86.76 & 4.3 & .11 \\
Intuitive & 26 & 84.32 & 5.1 & \\
Visual & 21 & 86.76 & 4.3 & .01 \\
Verbal & 24 & 83.31 & 5.4 & \\
Sequential & 25 & 85.4 & 3.2 & .73 \\
Global & 20 & 82.3 & 5.8 & \\
\hline Source: Calculated for this study & & &
\end{tabular}

\section{Table 3. Students' Posttest Achievement in the Augmented Reality Environment}

The results of the inferential analysis in this study showed that active learners perform better than reflective learners. According to Felder and Silverman (1988), active learners learn best by doing something before thinking and prefer group working, while reflective learners prefer to think about it quietly and work alone. Given these characteristics, the AR-enabled learners to experiment interactively with 3D human body structure as well as to observe the shape and location. It provided instant and reliable feedback. Therefore, AR technology gave active learners the opportunities to try and observe different options that match well with their learning styles.

In addition, the visual learners had better performance than the verbal learners. Visual learners preferred learning and solving problems through visualization, whereas the AR technology offered opportunities to understand the vivid $3 \mathrm{D}$ shape of human body organs. Informal observation of the AR among learners elicits very encouraging responses from them to achieve the immersive feel. Visual learners, therefore, benefited significantly from visual display, and reinforced their motivations to learn knowledge and experience. The findings supported the study of De Serio et al. (2013) who found that students improved learning outcomes through the visualization in a multimedia learning environment.

\section{LIMITATIONS}

There are at least two limitations in this study we would like to mention. First, the sample was quite 


\section{Shiue et al.}

small. Investigating larger population can provide more reliable results. Thus, the finding of this study should be interpreted cautiously. Hence, the results cannot be generalized or applied in other contexts and might only be applicable to contexts with similar characteristics. Second, AR applied only in four weeks of natural science course, it needs to take a long-term evaluation to investigate the effectiveness of the AR application and explore whether the effects of AR influencing the short-term memory instead long-term memory for students' learning process in the middle-school students.

\section{REFERENCES}

Azuma, R. T. (1997). A Survey of augmented reality. In Presence: Teleoperators and Virtual Environments, 6(4): 355-385.

Azuma, R., Baillot, Y., Behringer, R., Feiner, S., Julier, S. \& Maclntyre, B. (2001). Recent advances in augmented reality. IEEE Computer Graphics and Applications, 21(6): 34-47.

Bacca, J., Baldiris, S., Fabregat, R., Graf, S. \& Kinshuk (2014). Augmented reality trends in education: A systematic review of research and applications. Educational Technology and Society, 17(4): 133-149.

Brown, M. C., McNeil, M. N. \& Glenberg, A. M. (2009). Using concreteness in education: real problems, potential solutions. Child Development Perspectives, 3(3): 160-164.

Bujak, K. R., Radu, L., Maclntyre, B., Catrambone, R., Zhang, R. \& Golubski, G. (2013). A psychological perspective on augmented reality in the mathematics classroom. Computers and Education, 68, 536-544.

Campbell, L. C., Campbell, B. \& Dickinson, D. (2003). Teaching and learning through multiple intelligences (3 ${ }^{\text {th }}$ ed.). Needham Heights, MA: Allyn and Bacon

Chen, Y. C. (2006). A study comparing the use of augmented reality and physical models in chemistry education. In Proceedings of 2006 International Conference on Virtual Reality Continuum and its Application. Hong Kong, China.

Cheng, K. H., \& Tsai, C. C. (2012). Affordances of augmented reality in science learning: suggestions for future research. Journal of Science Education and Technology, 22(4): 449-462.

Cuendet, S., Bonnard, Q., Do-Lenh, S. \& Dillenbourg, P. (2013). Designing augmented reality for the classroom. Computer and Education, 68, 557-569.

De Serio, A., Ibanez, M. B. \& Kloos, C. D. (2013). Impact of an augmented reality for the classroom. Computers and Education, 68, 557-568.

Demir, M. (2015). Third grade elementary students' perception of science. International Electronic Journal of Elementary Education, 7(2): 157-168.

Dunn, R., Beaudry, J. S. \& Klavas, A. (2002). Survey of research on learning styles. California Journal of Science Education, 2(2): 75-98.

Dunleavy, M., Dede, C. \& Mitchell, R. (2009). Affordances and limitations of immersive participatory augmented reality simulations for teaching and learning. Journal of Science Education and Technology, 18(1): 7-22.

Fenrich, P. (2006). Getting practical with learning styles in "live" and computer-based settings. Issues in Informing Science and Information Technology, 3, 233-242.

Felder, R. M. \& Silverman, L. (1988). Learning and teaching styles in engineering education. Engineering Education, 78(7): 674681.

Felder, R. M. \& Soloman, B. A. (1991). Index of learning. North Carolina State University. Retrieved from http://www.engr.ncsu.edu/learningstyles/ilsweb.html

Felder, R. M. \& Spurlin, J. (2005). Application, reliability and validity for the index of learning styles. International Journal of Engineering Education, 21(1): 103-112.

Ganguly, P. K. (2010). Teaching and learning of anatomy in 21 Century: Direction and the strategies. The Open Medical Education Journal, 3, 5-10.

Huang, H. M., Rauch, U. \& Liaw, S. S. (2010). Investigating learners' attitudes toward virtual reality learning environments: based on a constructivist approach. Computers and Education, 55(3): 1171-1182.

Jamali, S. S., Shiratuddin, M. F., Wong, K. W. \& Oskam, C. L. (2015). Utilising mobile-augmented reality for learning human anatomy. Procedia Social and Behavioral Science, 197, 659-668.

Keefe, J. W. (1987). Learning style: Theory and practice. Reston: National Association of Secondary School Principals.

Kolb, D. A. (1984). Experiential learning: Experience as the source of learning and development. Englewood Cliffs, NJ: PrenticeHall.

Lee, R. T. (2010). Young children's conceptions of science and scientists. Doctoral Dissertation, University of Washington.

Lin, T. J., Duh, H. B. L., Li, N., Wang, H. Y. \& Tsai, C. C. (2013). An investigation of learners' collaborative knowledge construction performances and behavior patterns in an augmented reality simulation system. Computers and Education, 68, 314-321.

Ibáñez, M. B., Serio, Á. D., Villarán, D. \& Kloos, C. D. (2014). Experimenting with electromagnetism using augmented reality: Impact on flow student experience and educational effectiveness. Computers and Education, 71, 1-13. 
International Journal of Management, Economics and Social Sciences

Martin-Gutierrez, J., Luis, S. J., Contero, M., Alcaniz, M., Perez-Lopez, D. Z. \& Ortega, M. (2010). Design and validation of an augmented book for spatial abilities development in engineering students. Computers and Graphics, 34(1): 77-91.

Popescu, E. (2010). Adaption provisioning with respect to learning styles in a web-based educational system: An experimental study. Journal of Computer Assisted Learning, 26(4): 243-257.

Roussou, M. (2004). Learning by doing and learning through paly: an exploration of interactivity in virtual environment for children. ACM Computers in Entrainment, 2(1): 1-23.

Rasimah, C., Ahmad, A. \& Zaman, H. (2011). Evaluation of user acceptance of mixed reality technology. Australasian Journal of Educational Technology, 27, 1369-1387.

Shaw, R. S. (2012). A study of the relationships among learning styles, participation types, and performance in programming language learning supported by online forums. Computers and Education, 58(1): 111-120.

Tarng, W. \& Ou, K. L. (2012). A study of campus butterfly ecology learning system based on augmented reality and mobile learning. In IEEE Seventh International Conference on Wireless, Mobile and Ubiquitous Technology in Education.

Wang, L. (2007). Variation in learning styles in group of Chinese English as a foreign language learners. International Educational Journal, 8(2): 408-417.

Wu, H. K., Lee, S. W. Y., Chang, H. Y. \& Liang, J. C. (2013). Current status, opportunities and challenges of augmented reality in education. Computers and Education, 62, 41-49.

Yen, J. C., Tsai, C. H. \& Wu, M. (2013). Augmented reality in the higher education: Students' science concept learning and academic achievement in astronomy. Procedia - Social and Behavioral Sciences, 103(26): 165-173. 